\title{
Pengembangan Sistem Informasi Rawat Jalan dan Pelayanan Persalinan di Klinik Berbasis Web
}

\author{
Hendra Rohman ${ }^{1}$, Selin Sheralinda ${ }^{2}$ \\ Program Studi Rekam Medis dan Informasi Kesehatan, Politeknik Kesehatan Bhakti Setya Indonesia ${ }^{1,2}$ \\ hendrarohman@mail.ugm.ac.id ${ }^{1}$
}

\begin{abstract}
Diajukan 9 November 2019 Diperbaiki 21 Januari 2020 Diterima 26 Februari 2020 ABSTRAK

Latar belakang: Klinik pratama dan pelayanan persalinan Citra Madina merupakan pengembangan dari Bidan Praktek Mandiri yang menyelenggarakan pelayanan untuk pemeriksaan umum, wanita hamil, persalinan, pemeriksaan fisik, tindakan medis, dan hasil anamnesa. Sistem pengelolaan rekam medis berbasis kertas ketika proses pendaftaran dan pengisian formulir rekam medis, serta menggunakan microsoft excel saat menyimpan data sosial pasien dan alergi obat. Sistem yang ada memungkinkan riwayat data pelayanan tidak berkesinambungan.

Tujuan: Merancang sistem informasi rawat jalan dan pelayanan persalinan berbasis web.

Metode: Penelitian kualitatif mengikuti tahapan development sistem, metode waterfall. Responden dalam analisis kebutuhan sistem yaitu petugas

apoteker.

Hasil: Rancangan sistem informasi rawat jalan dan pelayanan persalinan berbasis web yang memiliki beberapa fasilitas yaitu login, pengelolaan data pasien umum, pemeriksaan ibu hamil dan melahirkan, data kelahiran bayi, data obat, data pembayaran, dan pelaporan.

Kesimpulan: Perancangan sistem informasi rawat jalan dan pelayanan persalinan berbasis web mampu memaksimalkan keamanan dari orang-orang yang tidak berhak mengakses sistem. Pengembangan sistem pada bidan praktek mandiri menjadi klinik pratama ini dapat digunakan untuk mengolah data pemeriksaan pasien umum, pemeriksaan ibu hamil, ibu melahirkan dan catatan kelahiran bayi, serta mampu mengolah laporan kunjungan, laporan penyakit, laporan obat dan laporan pembayaran.
\end{abstract} pendaftaran rawat jalan, dokter, bidan, dan

Kata Kunci: bidan praktek mandiri; klinik pratama; rekam medis; sistem informasi

\section{ABSTRACT}

Background: Citra Madina pratama clinic and childbirth service was a development of an independent practitioner midwife who provides services for general examinations, pregnant women, childbirth, physical examination, medical procedures and the results of anamnesa. The paper-based medical record management system compiles registration and fills out medical record forms and uses microsoft excel when storing patient social data and medicines. Systems that support data publication not sustainable.

Objective: To design an outpatient information system and delivery service web-based

Methods: Qualitative research follows the stages of system development, the waterfall method. Respondents in the system needs analysis are outpatient registration officers, doctors, midwives and pharmacists.

Results: The design of an outpatient information system and web-based delivery service that has several facilities, namely login, general patient data management, examination of pregnant and childbirth, baby birth data, drug data, payment data and reporting.

Conclusion: The design of outpatient information systems and delivery services web-based was able to maximize security of people who are not entitled to access the system. The development of the system in independent practice midwives into pratama clinics can be used to process data examinations of general patients, examinations of pregnant women, birth mothers and baby birth records and able to process visit reports, disease reports, drug reports and payment reports.

Keywords: independent practice midwives; pratama clinics; medical records; information systems 


\section{PENDAHULUAN}

Sistem informasi klinik merupakan sebuah sistem informasi yang meliputi proses penyimpanan dan pengambilan informasi, dalam membantu kegiatan pelayanan langsung pada pasien yang bertujuan memperoleh hasil akurat, mempercepat pelayanan, dan menghemat tenaga. Pelayanan langsung tersebut meliputi membantu dalam mendiagnosa suatu penyakit, membantu dalam monitoring perkembangan pasien, dan menbantu dalam penyesuaian terapi.

Klinik sebagai salah satu institusi pelayanan kesehatan umum membutuhkan keberadaan sistem informasi yang akurat dan andal, serta cukup memadai untuk meningkatkan pelayanan kesehatan kepada para pasien, serta lingkungan yang terkait lainnya. Pengelolaan data di institusi pelayanan kesehatan, merupakan salah satu komponen yang penting dalam mewujudkan sistem informasi klinik.

Sistem informasi klinik menjadi salah satu program baru dan sangat penting dalam bidang kesehatan. Seorang perekam medis memiliki data atau informasi penting yang berhubungan dengan pasien meskipun dalam lingkup kecil, tetapi hal ini sangat bermanfaat dalam menjalankan proses pemberian pelayanan kesehatan ataupun lainnya. Adanya sistem informasi manajemen klinik, diharapkan dapat membantu para tenaga kesehatan agar lebih mempermudah kegiatan pelayanan, dalam proses maupun dalam pencarian informasi. Sistem informasi manajemen klinik juga akan menghindari masalah yang mungkin bisa terjadi pada kegiatan rekam medis.

Inovasi manajemen dilakukan melalui beberapa masukan yang diperoleh dari pengguna, termasuk para pemangku bidang kesehatan, kepala klinik setempat, bidan, dokter obsgyn, dan staf kesehatan masyarakat. Sistem yang diimplementasikan dapat menjembatani kesenjangan antara kebutuhan klinis dan dokumentasi digital, pemantauan telemedicine dan meningkatkan kualitas perawatan pasien, memfasilitasi komunikasi baik dalam lingkup internal (perawatan kesehatan primer) dan eksternal (pemangku kepentingan dan tindak lanjut), meningkatkan produktivitas dan mengurangi biaya keseluruhan(Faried et al., 2015).

Penerapan pedoman pelayanan kesehatan yang ditetapkan oleh Kementerian Kesehatan bagi pelayanan ibu dan bayi baru lahir di fasilitas kesehatan primer, memerlukan dukungan teknologi informasi berupa sistem informasi untuk mendukung kelengkapan data, sehingga informasi yang dihasilkan lengkap. Hal ini disebabkan oleh adanya tuntutan kebutuhan informasi yang semakin meningkat, terutama terkait adanya permasalahan ketidaklengkapan data pada pelayanan klinis dan pelaporan bayi baru lahir. Hasil keluaran formulir bayi baru lahir dan surat keterangan kelahiran yang diinginkan oleh user, dipetakan dan menjadi output dari desain prototipe, sehingga hasil desain prototipe dapat menjadi solusi dari permasalahan yang ada (Karimah dan Wicaksono, 2018).

Pengolahan data pelayanan sering mendapatkan hambatan, diantaranya dalam proses pencarian data pasien, penyimpanan dokumen yang terbatas, pendapatan yang dapat dimanipulasi oleh bidan lain yang bekerja di BPJS (Anggoro dan Nofiyani, 2016). Pasien harus mendaftar sebagai pasien baru lagi jika ke puskesmas yang berbeda, pasien masih menggunakan buku KIA untuk mendapatkan informasi dan melihat catatan hasil konseling yang memiliki resiko rusak atau hilang, serta pasien kesulitan untuk melakukan monitoring terhadap perawatan kesehatannya (Jatmika, et al., 2019). Pelaporan menggunakan microsoft excel masih ditemukan kekurangan, yaitu data tidak konsisten, keterlambatan pengumpulan pelaporan, salah simpan data, hak akses digunakan semua pihak, dan duplikat data(Rohman dan Agnia, 2019).

Bidan desa memiliki masalah yang terkait dengan sistem pelaporan, termasuk inkonsistensi dalam pelaporan, buruknya 
akses ke riwayat pasien secara individu dan buruknya akses ke klinik. Masalah ini menghasilkan ketidaklengkapan dan ketepatan waktu transfer data yang buruk. Kualitas pelaporan data yang buruk dihasilkan dari metode pelaporan yang tidak konsisten (Ngana et al., 2012).

Peningkatan kesadaran masyarakat akan kesehatan yang berkorelasi langsung dengan meningkatnya kebutuhan masyarakat atas layanan kesehatan, Klinik Pratama, dan Pelayanan Persalinan Citra Madina selaku penyedia jasa layanan kesehatan ikut berpastisipasi untuk turut serta memenuhi harapan masyarakat. Klinik Pratama Rawat Jalan dan Pelayanan Persalinan Citra Madina, merupakan pengembangan dari Bidan Praktik Mandiri (BPM) sebagai fasilitas kesehatan yang bertujuan untuk memberikan pelayanan kesehatan kepada masyarakat yang berkualitas dan terjangkau. Pelayanan klinik melayani poli umum, persalinan 24 jam, pemeriksaan ibu hamil, kesehatan reproduksi, dan keluarga berencana.

Klinik Citra Madina merupakan klinik pratama dan pelayanan persalinan yang menyelenggarakan pelayanan untuk pemeriksaan umum, wanita hamil, persalinan, pemeriksaan fisik, pemberian tindakan medis, dan memberikan informasi hasil anamnesa. Klinik ini berdiri sejak tahun 2016. Klinik tersebut masih menggunakan sistem pengelolaan rekam medis manual ketika proses pendaftaran dan pengisian formulir rekam medis, serta menggunakan microsoft excel untuk menyimpan data sosial pasien dan alergi obat. Terdapat beberapa kekurangan dalam penggunaan microsoft excel tersebut yaitu tidak dapat digunakan untuk mendaftar pasien dan mencari data pasien lama, serta setiap orang masih dapat mengakses data pada sistem tersebut, sehingga keamanan data tidak dapat terjaga.

Aplikasi pengolahan data pasien membantu penyajian informasi secara cepat, tepat dan akurat (Haryanto dan Firmansyah, 2018). Sistem informasi laporan kunjungan dapat mengurangi kesalahan dalam pencatatan data kunjungan pasien (Pradhieka dan Samsinar, 2018; Soleha dan Samsinar, 2018). Rancangan sistem informasi electronic medical record (EMR) berbasis web digunakan untuk meningkatkan kualitas hasil diagnosa penyakit pasien(Aryani et al., 2018).

Pada Klinik Citra Madina, terdapat catatan dan dokumen tentang identitas pasien, pemeriksaan, pengobatan, tindakan, dan pelayanan lain yang telah diberikan kepada pasien yang tercatat pada berkas rekam medis. Namun, proses kegiatan rekam medis pada pendaftaran, pemeriksaan, farmasi, pembayaran, dan pengkodean penyakit masih dalam bentuk manual. Hal tersebut pada pelaksanaannya sering mengalami banyak kendala, diantaranya waktu yang tidak efisien, terjadi duplikasi nomor rekam medis, serta berkas rekam medis hilang, sehingga pelayanan yang diberikan kepada pasien menjaditidak efisien.

Sistem yang ada memungkinkan riwayat data pelayanan tidak berkesinambungan. Dengan adanya permasalahan tersebut diperlukan suatu sistem informasi manajemen klinik berbasis web yang mampu mengelola data secara efisien, dengan harapan dapat membantu mempermudah tenaga medis dan non medis dalam kegiatan pelayanan dan manajemen klinik. Pengembangan sistem pada bidan praktik mandiri menjadi klinik pratama tersebut terdiri dari pengolahan data pemeriksaan pasien umum, pemeriksaan ibu hamil, ibu melahirkan dan catatan kelahiran bayi, laporan kunjungan, laporan penyakit, laporan obat, dan laporan pembayaran.

\section{METODE}

Implementasi kode program dilakukan dengan menggunakan PHP Strom v.2019.1.3 untuk code editor dan bantuan framework bootstrap serta material untuk merancang antar muka. Framework codeigniter v3.1 untuk koneksi dengan basis data. MySQL v5.7.24 digunakan untuk membuat basis data.

Penelitian ini menggunakan development 
sistem, metode waterfall. Pengambilan data dengan purposive sampling. Pengumpulan data dilakukan melalui wawancara kepada tenaga kesehatan yang dianggap kompeten serta mempunyai wewenang untuk mengoperasikan sistem informasi manajemen klinik, yaitu petugas pendafataran rawat jalan, dokter, bidan, dan apoteker. Observasi dan studi dokumentasi dilakukan terhadap pelaksanaan kegiatan pengolahan data rekam medis pasien.

\section{HASIL DAN PEMBAHASAN}

Pada sistem informasi rawat jalan dan pelayanan persalinan berbasis web terdapat 5 pengguna sistem, yaitu pimpinan klinik sebagai admin, petugas pendaftaran, dokter, bidan, dan farmasi. Alur pelayanan dimulai ketika pasien datang ke klinik untuk mendapatkan pelayanan kesehatan yang akan dilayani oleh petugas pendaftaran. Kemudian, petugas pendaftaran menanyakan apakah pasien tersebut sudah pernah melakukan kunjungan untuk berobat di Klinik Citra Madina atau belum. Jika pasien sudah pernah berobat, maka petugas pendaftaran akan mencari data sosial pasien, jika pasien belum pernah berobat maka petugas pendaftaran dapat melakukan input data pasien, lalu menyimpannya. Setelah data sosial pasien tersimpan pada sistem, maka dokter atau bidan akan melakukan cek data pasien yang telah terdaftar. Selanjutnya dokter atau bidan akan melakukan pemeriksaan kepada pasien dan melakukan input hasil pemeriksaan ke dalam sistem tersebut.

Hasil dari pemeriksaan akan diolah oleh petugas pendaftaran menjadi laporan penyakit yang akan dilaporkan kepada puskesmas terdekat, tetapi pelaporan yang dikumpulkan pada sistem informasi manajemen klinik tidak hanya laporan penyakit, namun juga laporan kunjungan pasien yang berkunjung untuk berobat di Klinik Citra Madina. Setelah melakukan input hasil pemeriksaan, hal selanjutnya yang dilakukan dokter atau bidan yaitu membuat resep obat yang akan diberikan kepada pasien. Kemudian, petugas farmasi akan mengelola data obat, menyiapkan kebutuhan obat yang akan diberikan kepada pasien sesuai dengan resep yang sudah ditulis dokter, merinci biaya obat, serta biaya pelayanan yang telah diberikan kepada pasien.

\section{A. Rancangan Context Daigram, DFD, UML, dan} ERD.

Berikut rancangan context diagram, data flow diagram (DFD), unified modeling language (UML) activity, unified modeling language (UML), dan entity relationship diagram (ERD):

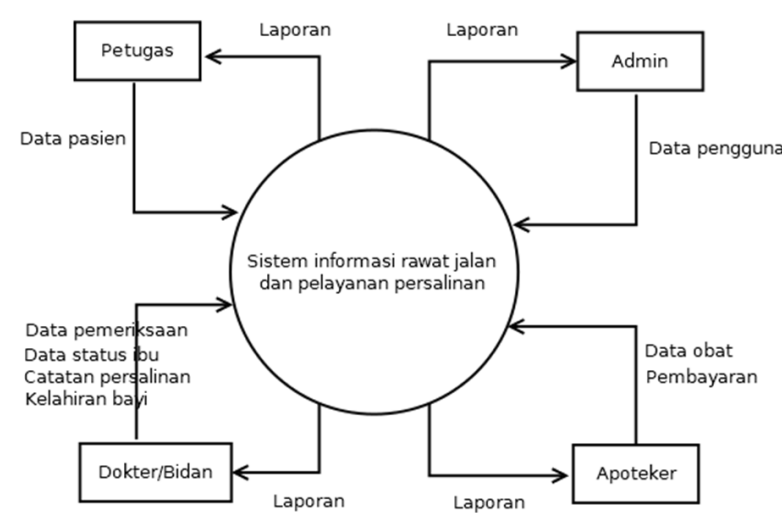

Gambar 1. Context diagram sistem informasi rawat jalan dan pelayanan persalinan 
a) Rancangan data flow diagram (DFD)

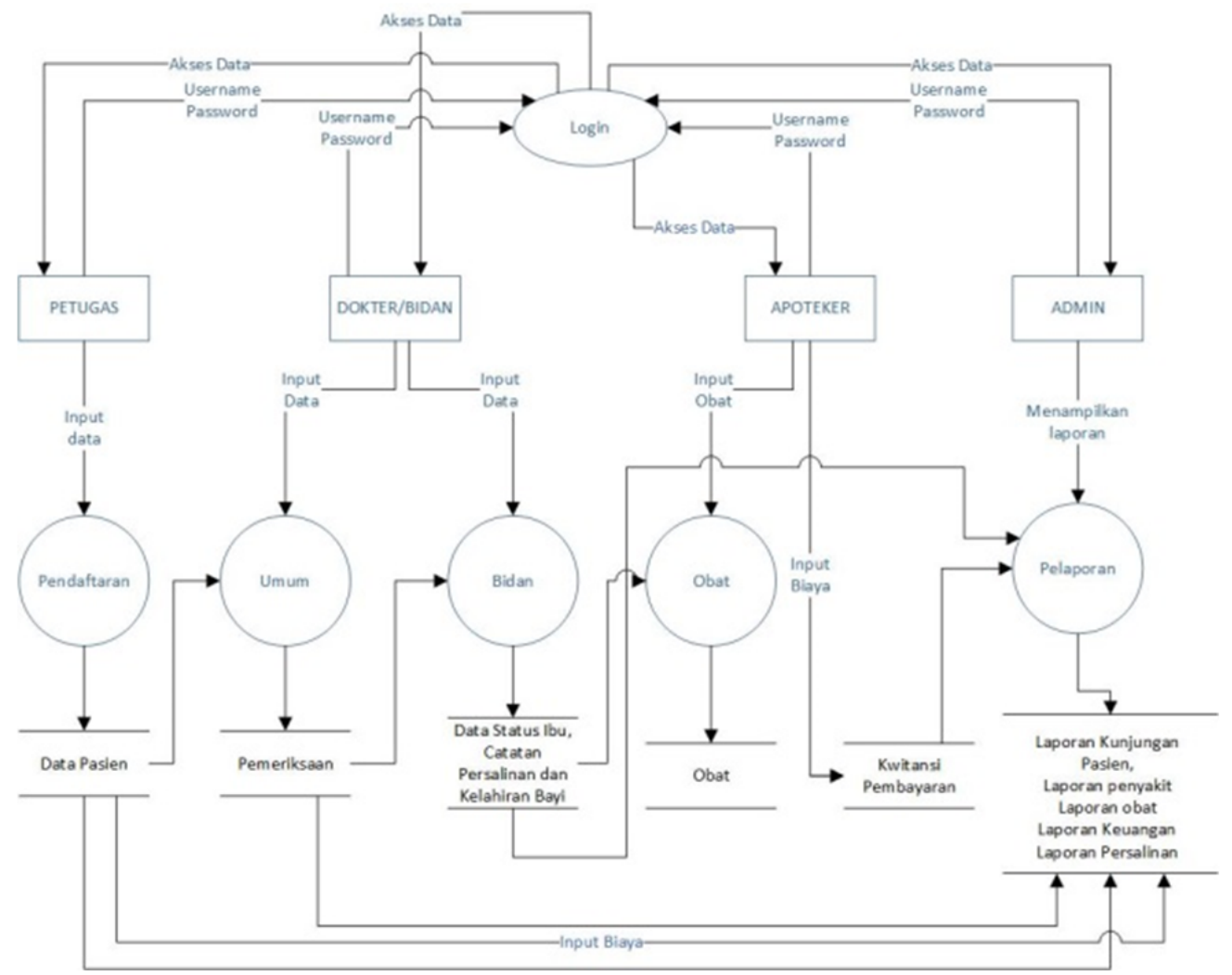

Gambar 2. DFD sistem informasi rawat jalan dan pelayanan persalinan

b) Rancangan unified modeling language (UML)

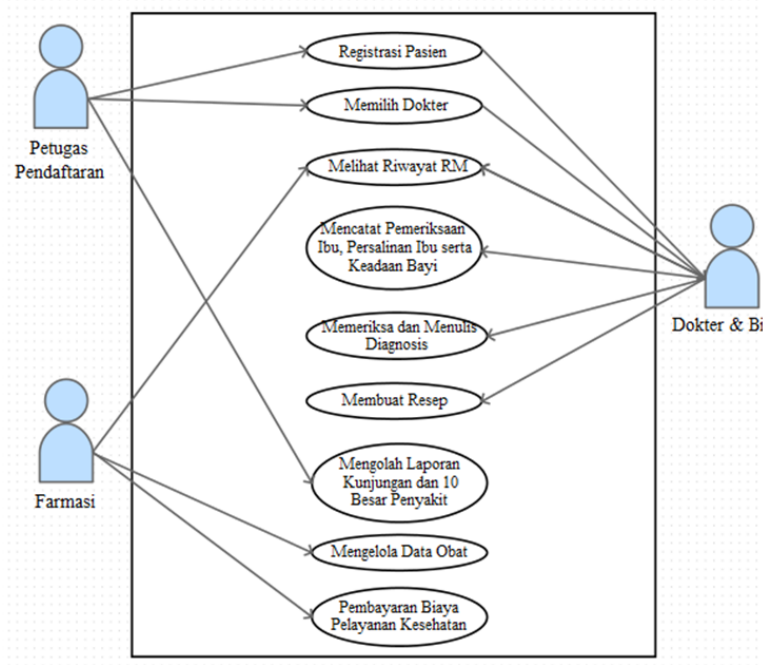

Gambar 3. UML sistem informasi rawat jalan dan pelayanan persalinan c) Rancangan unified modeling language (UML) activity

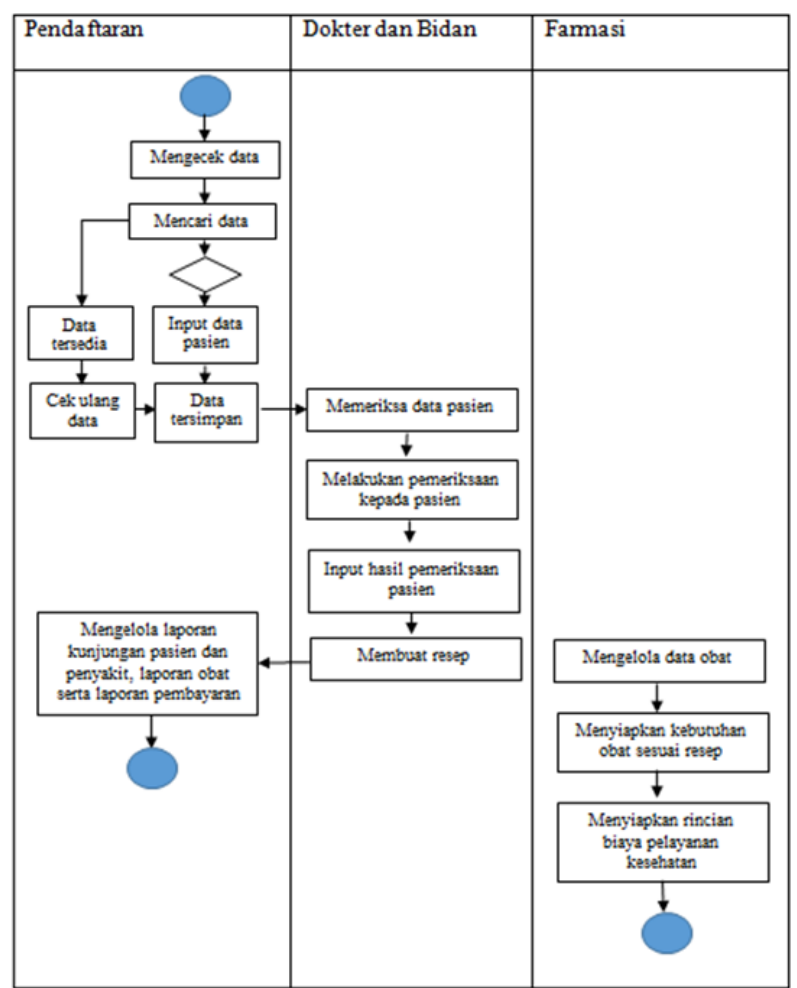

Gambar 4. UML activity sistem informasi rawat jalan dan pelayanan persalinan 
e) Rancangan entity relationship diagram ( $E R D$ )

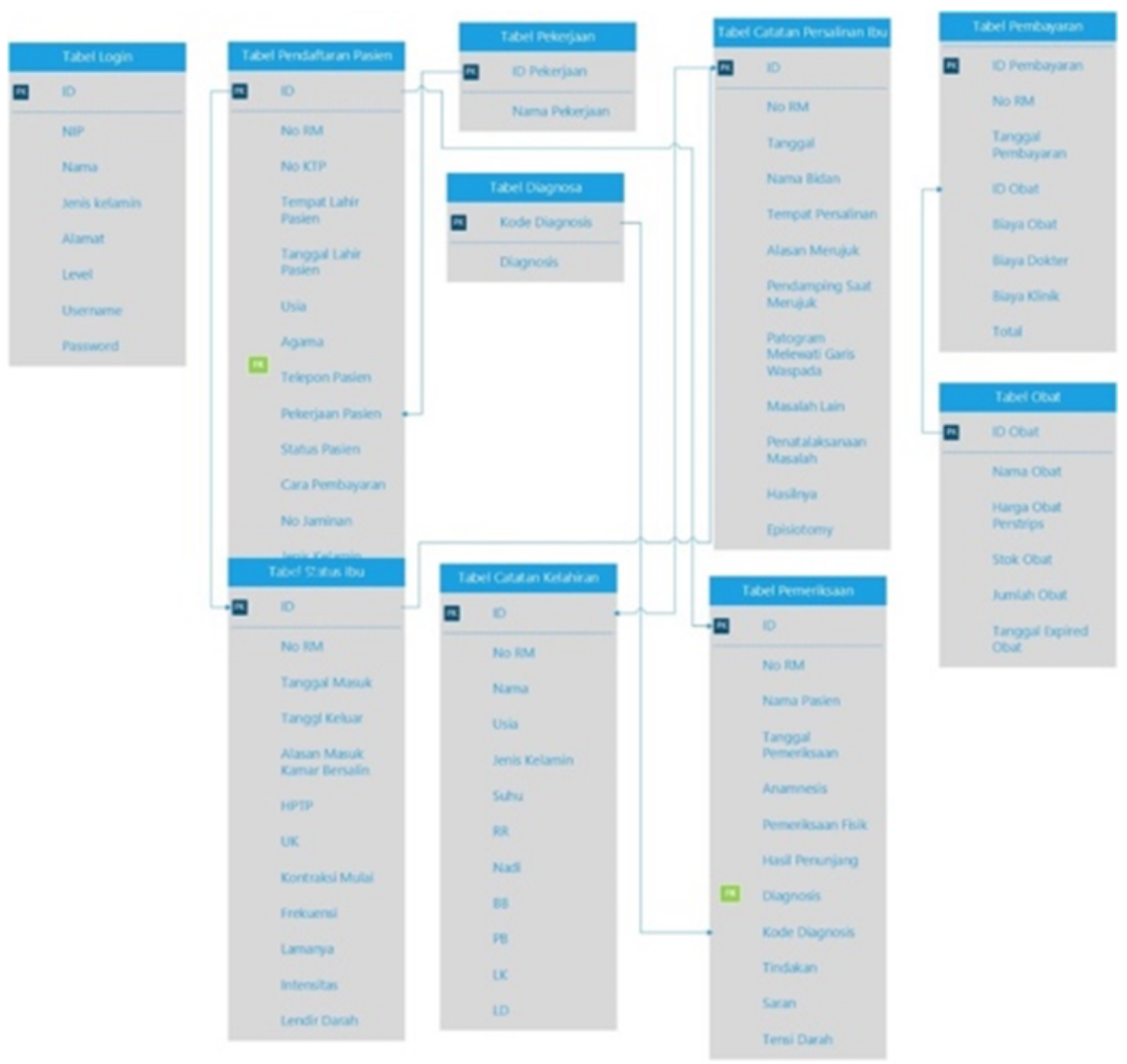

Gambar 5. ERD sistem informasi rawat jalan dan pelayanan persalinan

Desain Entity Relation Diagram (ERD) yang merupakan suatu model jaringan kerja (network) yang menguraikan susunan data yang disimpan dari sistem secara abstrak. Prototipe pendukung kelengkapan data pelayanan klinis bayi baru lahir di FKTP menjelaskan hubungan antar data dalam basis data, yang mempunyai hubungan antar relasi yaitu antara entitas nakes (tenaga kesehatan) dalam hal ini bidan atau dokter penanggungjawab pelaksana pelayanan dengan entitas pasien, pelayanan dan formulir bayi (Karimah dan Wicaksono, 2018).

Kebutuhan desain interface atau tampilan antar muka dibuat menggunakan prinsip simplicity, consistency, dan familiarity. Simplicity, dimana sistem didesain sesederhana mungkin untuk mempermudah calon pengguna dalam pengoperasian. Consistency, dalam pemilihan warna, font dan menu konsisten, sehingga pengguna tidak kesulitan untuk memahami. Pemilihan warna yang digunakan yaitu perpaduan antara putih dan biru muda. Font yang digunakan yaitu jenis font arial dan menu yang ditampilkan memudahkan dalam penggunaan sistem. Familiriaty, berarti desain sesuai dengan lembar dan formulir pelayanan pratama dan persalinan yang ada sebelumnya, sehingga calon pengguna lebih cepat dan tidak kesulitan untuk melakukan input data karena telah sesuai dengan yang diperlukan. 
B. Hasil Implementasi dan Pengujian Sistem

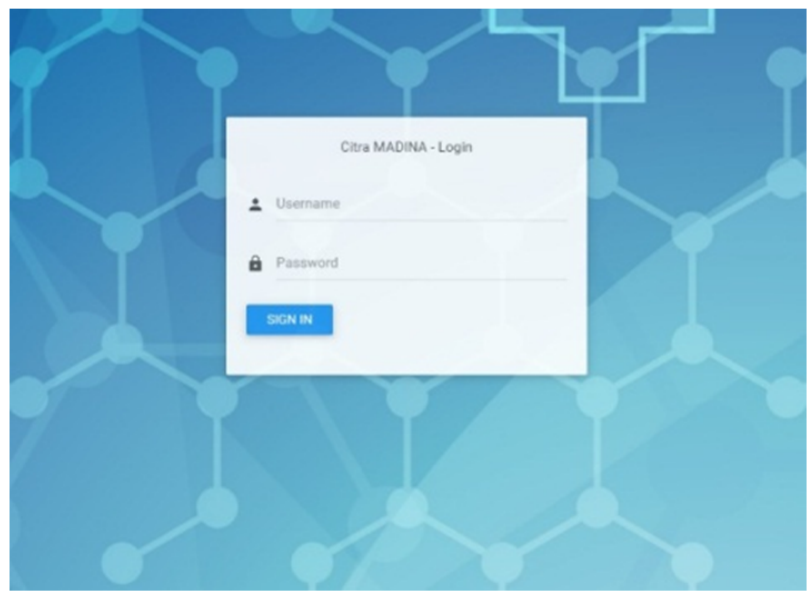

Gambar 6. Halaman menu login

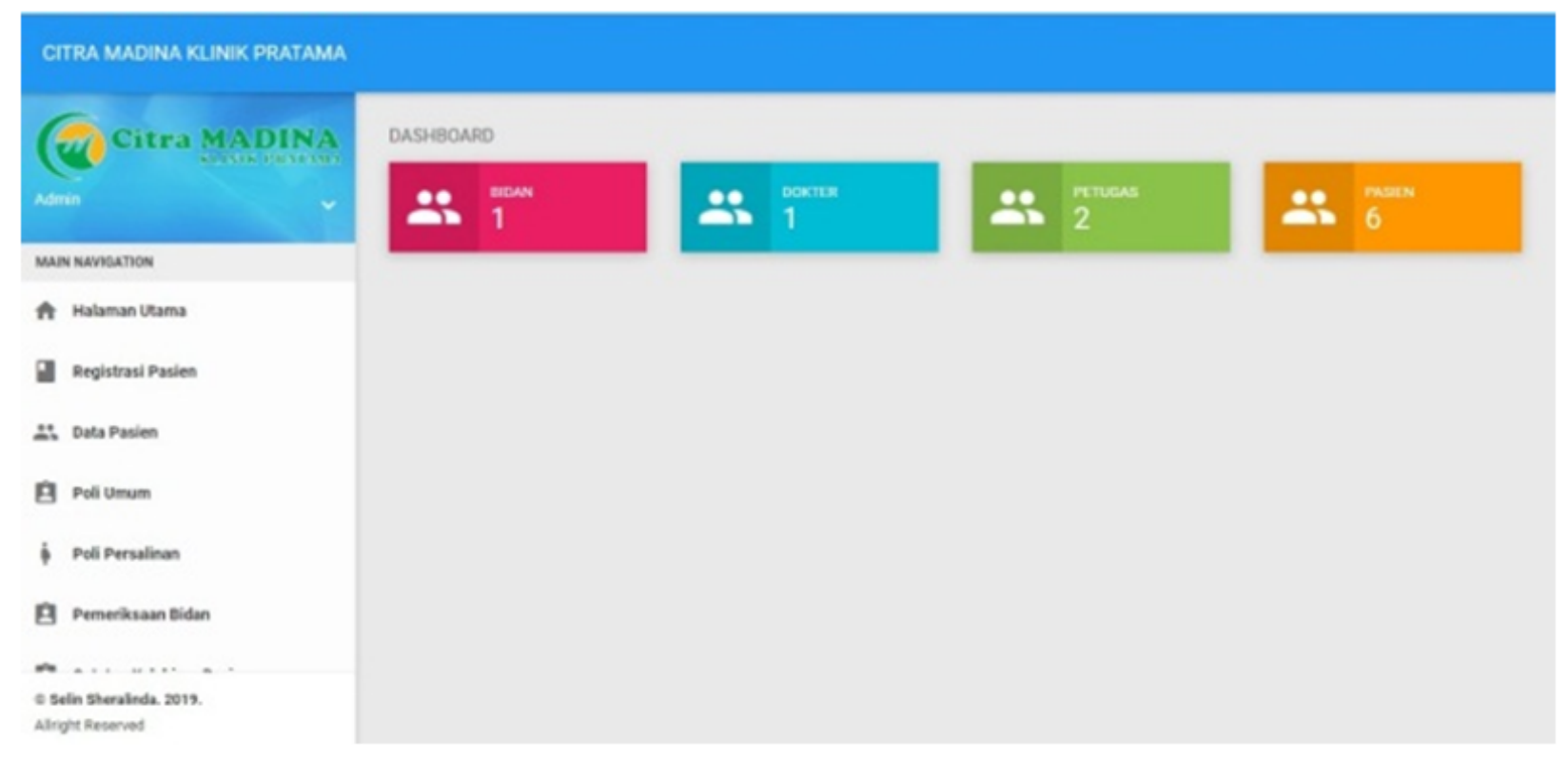

Gambar 7. Tampilan menu utama

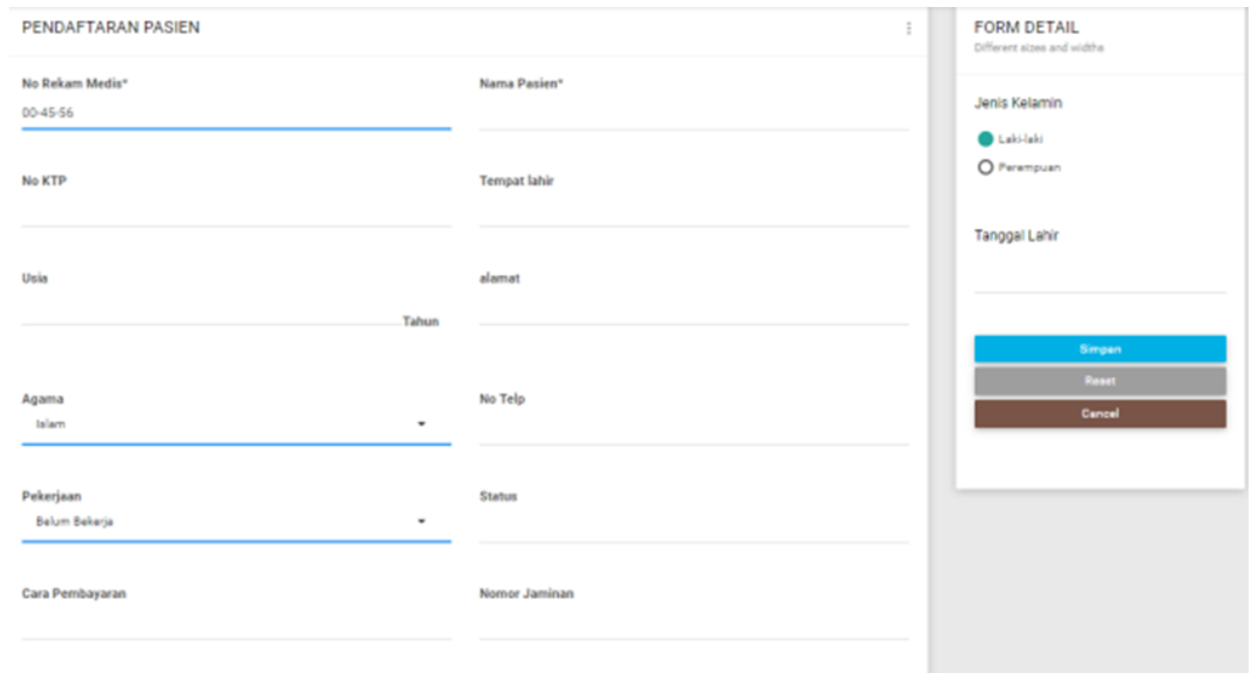

Gambar 8. Tampilan halaman pendaftaran pasien 


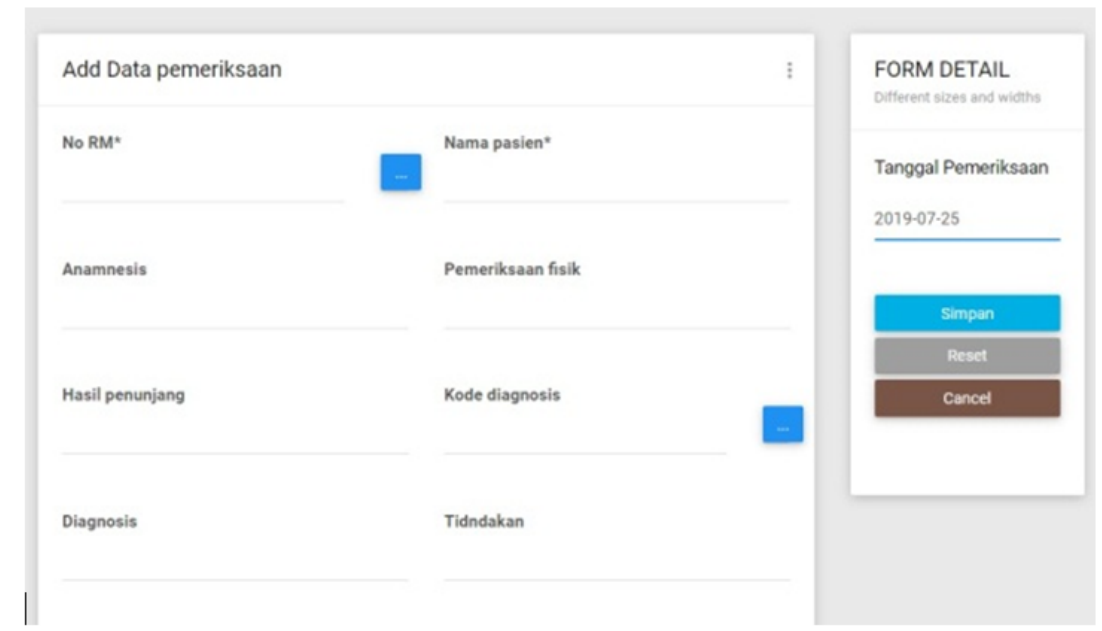

Gambar 9. Tampilan pada halaman pemeriksaan

\section{a. Halaman login}

Halaman login merupakan proses untuk mengakses sebuah sistem dengan cara memasukkan identitas pengguna beserta kata sandi (password). Fungsi halaman login adalah pintu masuk ke dalam sistem yang telah dibuat sehingga kita bisa masuk ke halaman utama serta memanfaatkan fasilitas yang ada di dalamnya.

Sistem sebelumnya, hak akses untuk proses pendaftaran pasien umum maupun persalinan dapat diakses oleh siapapun. Keamanan sistem dalam proses input data pasien tidak ada. Hal ini memungkinkan akses bagi pihak yang tidak berwenang.

\section{b. Halaman menu utama}

Halaman menu utama menampilkan menu yang dapat diakses oleh pengguna sistem informasi manajemen klinik berbasis web. Admin dapat mengakses seluruh menu. Dokter dapat mengakses menu pemeriksaan umum. Bidan dapat mengakses menu pemeriksaan status ibu, catatan persalinan ibu dan catatan kelahiran bayi. Petugas pendaftaran dapat mengakses menu pendaftaran pasien (registrasi pasien) dan apoteker dapat mengakses menu data obat dan pembayaran. Konsep interface design menerapkan prinsip simplicity, consistency, dan familiarity.

Input sistem terdiri dari menu pendaftaran pasien baru, catatan kehamilan, rencana persalinan, catatan kelahiran, catatan nifas, catatan pemeriksaan anak, catatan imunisasi, dan catatan pemberian vitamin A (Pratiwi dan Rokhman, 2017). Penyusunan layout perlu dilakukan dengan teliti guna menentukan karakterisik (bentuk, ukuran, posisi) yang tepat dan menyatu sebagai sebuah tampilan "(Miharti dan Rohmasari, 2018).

Input terdiri dari input data registrasi, data pasien, perhitungan taksiran persalinan, berat janin, sedangkan output berupa laporan data pasien, registrasi, perkiraan persalinan, dan taksiran berat janin (Swastina dan Rizki, 2019). Data yang tersedia di dalam SIM KIA hanya berupa data catatan medik pasien seperti data calon istri, calon suami, data kehamilan, pemeriksaan kehamilan, kunjungan nifas, konsultasi KB, anamnesa, pemeriksaan fisik, tindakan, dan resep obat. Kemampuan SIM KIA dalam mengelola data seperti menghitung cakupan pelayanan belum bisa dihandalkan. Output dari SIM KIA hanya berupa data akumulasi catatan medik pasien (by name) dalam bentuk tabel(Swastina dan Rizki, 2019).

\section{c. Halaman pendaftaran pasien}

Halaman pendaftaran pasien merupakan halaman yang digunakan untuk memasukkan data pasien yang berobat dan setiap pasien yang mendaftar diberikan satu nomor rekam medis sebagai satu berkas untuk menyimpan data pasien tersebut, baik data sosial maupun data medis. Data yang dimasukkan pada 
halaman pendaftaran pasien yaitu nomor rekam medis, nama, nomor KTP atau NIK, tempat tanggal lahir pasien, usia, alamat, jenis kelamin, agama, nomor telepon, pekerjaan, status pasien, cara pembayaran, dan nomor jaminan jika pasien mempunyai jaminan kesehatan BPJS.

Pada sistem sebelumnya, data yang diisikan hanya nomor rekam medis, tanggal lahir, alamat, nomor telepon, dan alergi obat. Data tersebut belum sesuai dengan kebutuhan.

\section{d. Halaman data pengguna}

Halaman data pengguna pada sistem informasi manajemen klinik berfungsi untuk menyimpan data pengguna sistem informasi yang bertugas. Pada halaman ini, terdapat 5 level sebagai kategori dalam mengakses sistem informasi yaitu admin, dokter, bidan, petugas pendaftaran, dan apoteker. Bila pengguna seorang dokter, maka data yang dimasukkan pada halaman data dokter yaitu: NIP dokter, nama dokter, jenis kelamin level (dokter), alamat dokter, username, dan password.

Sistem sebelumnya, tidak terdapat level kategori hak akses sistem. Data dokter tidak ada, sehingga tidak dapat diketahui siapa dokter sebelumnya yang telah menangani pasien.

\section{e. Halaman pemeriksaan umum}

Halaman pemeriksaan umum pada sistem informasi manajemen klinik berfungsi untuk menyimpan data hasil pemeriksaan yang dilakukan oleh dokter kepada pasien yang berobat. Data yang dimasukkan pada halaman data petugas yaitu nomor rekam medis, nama pasien, tanggal pemeriksaan, anamnesis, pemeriksaan fisik, hasil penunjang, diagnosis, kode diagnosis, tindakan, saran, tensi darah, detak jantung, suhu badan, berat badan, dan dokter yang memberikan pelayanan.

Sistem terkomputerisasi melalui penyimpanan data yang telah menggunakan database, dokumen atau penyimpanan data bidan yang tersimpan lebih banyak, dan dapat meminimalisasi kesalahan pada penggunaan kertas (Soleha \& Samsinar, 2018). Sistem dapat mengumpulkan data pelayanan ibu dan prenatal untuk memantau kualitas layanan kesehatan dan analisis data saat melakukan intervensi awal yang dilakukan oleh dokter, bidan dan pihak berwenang (Djuwantono et al., 2016).

\section{f. Halaman pemeriksaan status ibu}

Halaman pemerikasaan status ibu pada aplikasi sistem informasi manajemen klinik berfungsi untuk menyimpan data hasil pemeriksaan pada ibu hamil yang dilakukan oleh bidan. Data tersebut yaitu nomor rekam medis, tanggal masuk dan keluar klinik, alasan masuk kamar bersalin, hari pertama haid terakhir (HPTP), hari perkiraan lahir (HPL), umur kehamilan (UK), waktu mulai kontraksi atau kontraksi mulai, frekuensi, lama frekuensi, intensitas, lendir darah, waktu, air ketuban, waktu, menarche, cyclus, lama, G, P, $\mathrm{AB}$, tahun lahir, jenis kelamin, keterangan, $\mathrm{KU}$, BB, TB, tensi, nadi, suhu, nafas, inspeksi kepala, muka, mata, leher, dada, perut, palpasi LI, LII, LIII, LIV, His freekuensi, Lamanya, HI intensitas, auscultasi detak jantung janin, frekuensi, genitalia, varices, reflek patella, HB, golongan darah pada pasien ibu hamil. Berikut tampilan pada halaman status ibu:

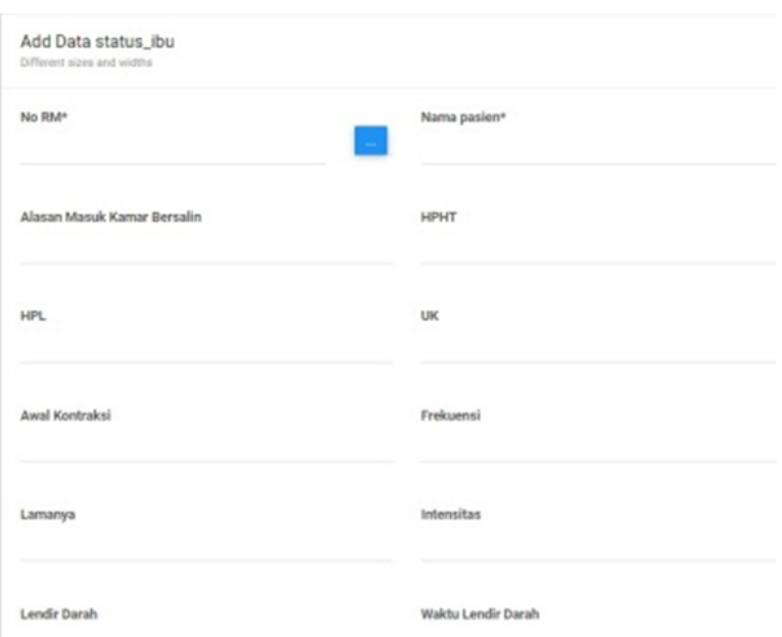

Gambar 10. Tampilan pada halaman status ibu

g. Halaman catatan persalinan ibu

Halaman catatan persalinan ibu pada 
sistem informasi manajemen klinik berfungsi untuk menyimpan data dari hasil persalinan ibu. Data tersebut yaitu nomor rekam medis, tanggal, nama bidan, tempat persalinan, catatan, alasan merujuk, tempat rujukan, pendamping saat merujuk, patogram melewati garis waspada, masalah lain, penatalaksanaan masalah, hasilnya, episiotomy, indikasi, pendamping persalinan, gawat janin, tindakan, hasil, distosia bahu, tindakan yang dilakukan, masalah lain, penatalaksanaan masalah tersebut, hasil, inisiasi menyusui dini, alasan, lama kala III, pemberian oksitosin, waktu, alasan, penjepitan tali pusar, pemberian ulang oksitosin, alasan, penegangan tali pusar terkendali, alasan, massage fundus uteri, alasan, plasenta lahir lengkap, tindakan, laserasi, dimana, derajat laserasi perineum, tindakan, alasan atoni uteri, tindakan, jumlah pendarahan, masalah lain, penatalaksanaan masalah tersebut, jam ke, waktu, tekanan darah, nadi, tinggi fundus uteri, kontraksi uterus, kandung kemih, hingga adanya pendarahan atau tidak. Berikut ini adalah tampilan pada halaman catatan persalinan ibu:

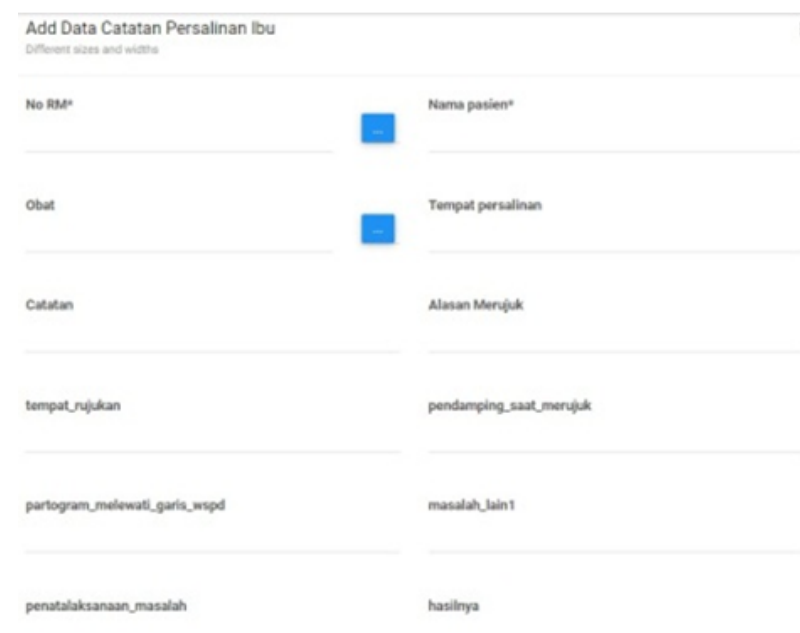

\section{Gambar 11. Tampilan pada halaman catatan persalinan ibu}

\section{h. Halaman catatan kelahiran bayi}

Halaman catatan kelahiran bayi pada sistem informasi manajemen klinik berfungsi untuk menyimpan data dari hasil pemeriksaan bayi baru lahir mulai dari nomor rekam medis, nama, usia, jenis kelamin, suhu, RR, nadi, BB,
PB, LK, LB, lila, kepala, mata, hidung, mulut, telinga, leher, dada, perut, genitalia, punggung, extremitas, penilaian bayi baru lahir, bayi lahir normal, aspiksia, tindakan, cacat bawaan, hipotermi, tindakan, pembagian asi, waktu, alasan, masalah lain. Berikut tampilan pada halaman catatan kelahiran bayi:

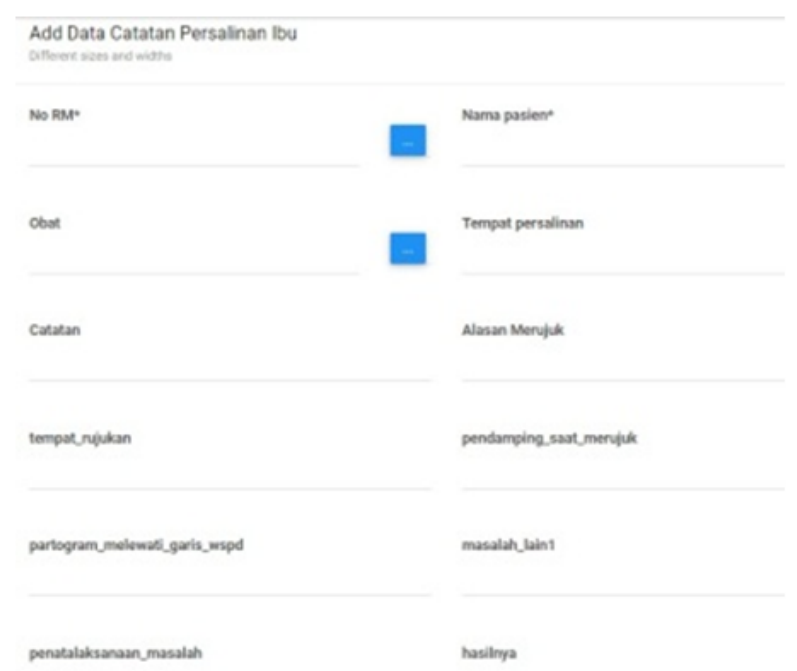

Gambar 12. Tampilan pada halaman catatan kelahiran bayi

\section{i. Halaman data obat}

Halaman data obat pada sistem informasi manajemen klinik berfungsi untuk menyimpan data obat. Data obat memuat informasi tentang nama obat, harga obat per strips, stok obat, jumlah obat, tanggal expired obat.

Sistem entry data obat dan transaksi dapat melakukan perhitungan serta update data obat, sehingga stok obat dapat terkontrol dengan baik dan pasien selalu akan mendapatkan obat dan stok obat tidak akan pernah kosong (Pradhieka \& Samsinar, 2018). Tinjauan terhadap penggunaan obat pada ibu di awal kehamilan sangat penting. Bidan dan perawat harus mengetahui sistem pelaporan kejadian buruk obat, termasuk register anomali bawaan(Morgan et al., 2011).

\section{j. Halaman pembayaran}

Halaman pembayaran pada sistem informasi manajemen klinik berfungsi untuk menyimpan data pembayaran biaya pelayanan klinik. Data tersebut yaitu ID pembayaran, nomor rekam medis, tanggal pembayaran, ID 
obat, biaya obat, biaya dokter, biaya klinik, total pembayaran.

Rancangan sistem informasi yang melakukan perhitungan biaya secara otomatis dapat mengurangi kesalahan bidan dalam perhitungan biaya pemeriksaan dan obat (Pradhieka dan Samsinar, 2018; Soleha dan Samsinar, 2018). Sistem ini mampu mengelola data biaya yang harus dikeluarkan selama pasien mendapatkan pelayanan.

\section{k. Halaman pelaporan}

Halaman pelaporan pada sistem informasi manajemen klinik berfungsi untuk menyimpan data pelaporan. Data tersebut yaitu laporan kunjungan pasien, laporan penyakit, laporan obat dan laporan pembayaran.

Melalui sistem laporan KB, bidan dapat mengetahui pasien yang harus berkunjung kembali (Pradhieka dan Samsinar, 2018). Sosialisasi sistem pelaporan kesehatan kepada semua staf yang terlibat, dapat meningkatkan konsistensi dan kelengkapan data. Sistem yang efektif untuk transfer data dan pelaporan, dapat mengurangi waktu yang dihabiskan beberapa petugas untuk tugas mereka. Peningkatan keakuratan data dan ketersediaan riwayat pasien individu memiliki potensi dalam peningkatan pelayanan kesehatan (Ngana et al., 2012).

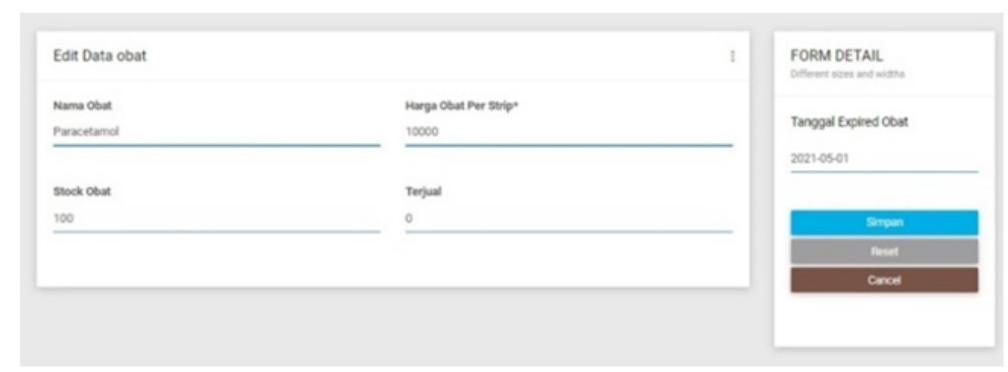

Gambar 13. Tampilan pada halaman obat

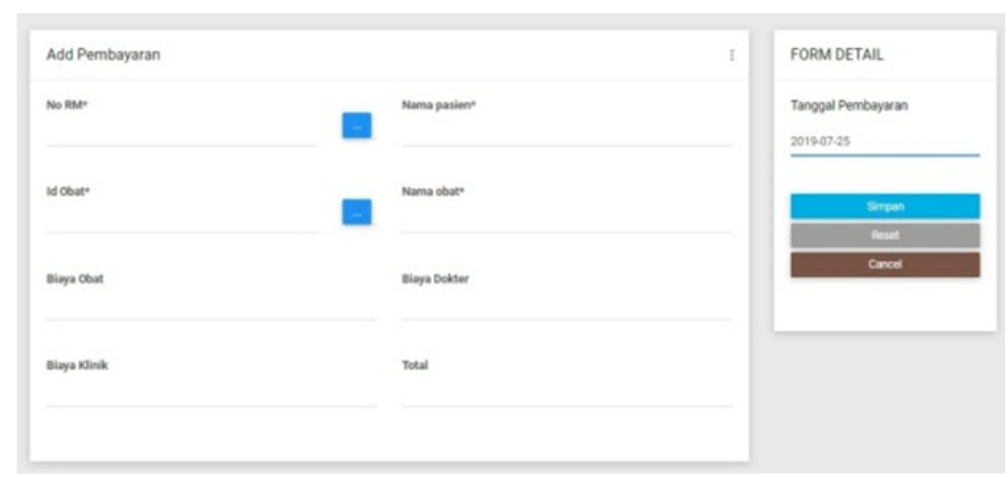

Gambar 14. Tampilan halaman pembayaran

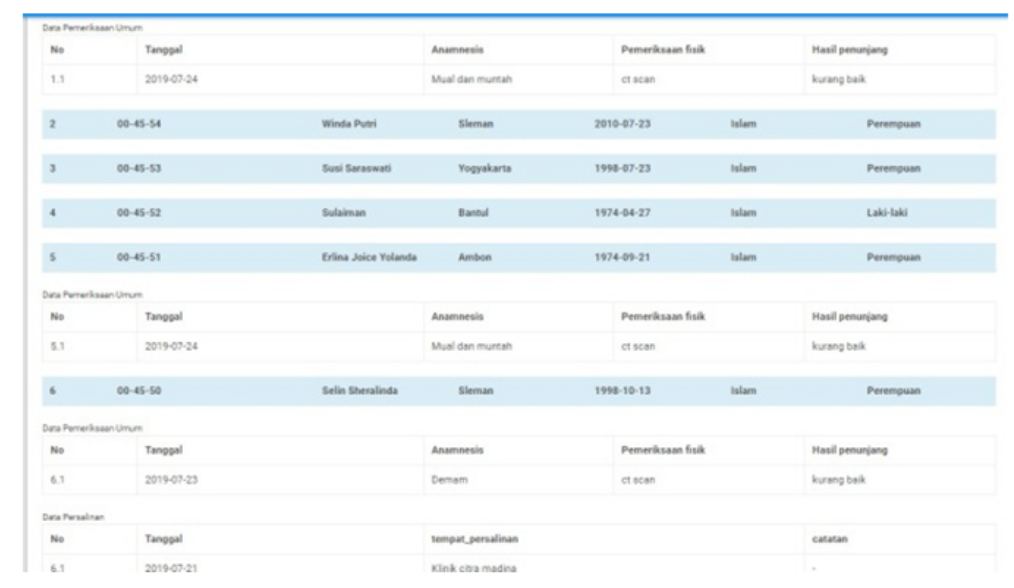

Gambar 15. Tampilan halaman pelaporan 
Pada sistem sebelumnya, data belum dapat dilakukan backup secara berkala, sehingga apabila tiba-tiba terjadi kerusakan atau error pada komputer akan menyebabkan data pasien yang sudah disimpan hilang. Pada sistem yang baru sudah terdapat fitur back up dan restore untuk menangani hal tersebut.

Kartu Identitas Berobat (KIB) pada sistem yang lama, masih dituliskan secara manual oleh petugas pendaftaran. Hal ini dapat memungkinkan terjadi kerusakan pada KIB dan tulisan tidak dapat terbaca. Pada sistem yang baru terdapat fitur cetak kartu identitas berobat, sehingga kualitas KIB lebih baik.

Kegiatan pengujian yang dilakukan adalah menggunakan blackbox testing. Pengujian ini dilakukan dengan menjalankan sistem informasi untuk memastikan apakah sistem berjalan dengan baik sesuai dengan requipment yang telah ditetapkan sebelumnya, seperti fungsi input, process dan output yang dihasilkan.

\section{Tabel 1. Blackbox testing}

\begin{tabular}{|c|c|c|c|c|}
\hline No & Pengujian & Skenario uji & Hasil & Hasil uji \\
\hline 1 & Menu login & $\begin{array}{l}\text { Input user } \\
\text { dan password }\end{array}$ & $\begin{array}{l}\text { Menampilkan } \\
\text { halaman } \\
\text { utama }\end{array}$ & Berhasil \\
\hline 2 & $\begin{array}{l}\text { Menu } \\
\text { pendaftaran }\end{array}$ & $\begin{array}{l}\text { Melakukan } \\
\text { registrasi } \\
\text { pasien baru }\end{array}$ & $\begin{array}{l}\text { Menyimpan } \\
\text { data registrasi } \\
\text { pasien }\end{array}$ & Berhasil \\
\hline 3 & $\begin{array}{l}\text { Menu } \\
\text { pemeriksaan } \\
\text { umum }\end{array}$ & $\begin{array}{l}\text { Input data } \\
\text { pemeriksaan } \\
\text { umum }\end{array}$ & $\begin{array}{l}\text { Menyimpan } \\
\text { data } \\
\text { pemeriksaan } \\
\text { pasien umum }\end{array}$ & Berhasil \\
\hline 4 & $\begin{array}{l}\text { Menu } \\
\text { pemeriksaan } \\
\text { status ibu }\end{array}$ & $\begin{array}{l}\text { Input data } \\
\text { pemeriksaan } \\
\text { status ibu }\end{array}$ & $\begin{array}{l}\text { Menyimpan } \\
\text { data } \\
\text { pemeriksaan } \\
\text { status ibu }\end{array}$ & Berhasil \\
\hline 5 & $\begin{array}{l}\text { Menu } \\
\text { catatan } \\
\text { persalinan }\end{array}$ & $\begin{array}{l}\text { Input data } \\
\text { catatan } \\
\text { persalinan } \\
\text { ibu }\end{array}$ & $\begin{array}{l}\text { Menyimpann } \\
\text { data } \\
\text { persalinan }\end{array}$ & Berhasil \\
\hline 6 & Menu obat & $\begin{array}{l}\text { Input data } \\
\text { obat }\end{array}$ & $\begin{array}{l}\text { Menyimpan } \\
\text { data obat }\end{array}$ & Berhasil \\
\hline 7 & $\begin{array}{l}\text { Menu } \\
\text { pembayaran }\end{array}$ & $\begin{array}{l}\text { Input data } \\
\text { pembayaran }\end{array}$ & $\begin{array}{l}\text { Mampu } \\
\text { melakukan } \\
\text { pembayaran }\end{array}$ & Berhasil \\
\hline
\end{tabular}

Perbandingan antara penggunaan microsoft excel dengan sistem informasi rawat jalan dan pelayanan persalinan berbasis web yaitu pada fitur hak akses, pada microsoft excel masih dapat dioperasikan atau digunakan oleh semua orang tanpa melalui proses login sedangkan pada sistem informasi berbasis web yang telah dirancang, terdapat menu login untuk memaksimalkan keamanan saat masuk ke dalam sistem, yang terbagi menjadi dua kategori yaitu admin dan $u s e r$.

Efektivitas input, pada microsoft excel pada proses pendaftaran yang dimulai dari pengisian nomor rekam medis, alamat, usia, dan lainnya masih dilakukan secara manual. Tidak hanya itu, pada input pelaporan juga dilakukan manual. Pada sistem informasi berbasis web yang telah dirancang terdapat proses input yang dimulai dari kegiatan pendaftaran pasien, pemeriksaan umum, pemeriksaan status ibu, catatan persalinan ibu, catatan kelahiran bayi, sampai dengan data pembayaran, yang mampu dilakukan secara otomatis.

Aplikasi web dapat memfasilitasi bidan untuk melakukan pencatatan transaksi, pembuatan laporan, dan penyampaian informasi kepada pasien (Kusuma, Shodiq, Yusuf, dan Saadah, 2019).

Sistem informasi medical record ibu hamil dan anak dirancang untuk lebih mempermudah pendataan dan pendokumentasian hasil pemeriksaan ibu hamil, sehingga lebih mempermudah manajemen puskesmas untuk mengambil tindakan jika diperlukan, seperti adanya surat rujukan ke rumah sakit yang lebih lengkap peralatannya. Dengan sistem ini jika ibu hamil lupa membawa buku pasien atau kartu pasien maka tidak perlu khawatir, karena puskesmas melalui bidan dan dokter bahkan ibu hamil sendiri dapat login ke sistem informasi rekam medis dan informasi terkait kunjungan terakhir pemeriksaan dan keluhan yang terjadi selama kehamilan dapat dilihat dilayar monitor dan dapat di cetak(Kraugusteeliana dan Krisnanik, 2018).

Aplikasi dirancang untuk membantu tenaga medis khususnya di bagian pelayanan persalinan dan rujukan persalinan dalam mengelola data pasien. Dengan adanya aplikasi ini dapat membantu mempercepat pengurangan AKI, dikarenakan puskesmas yang memiliki aplikasi ini dapat memberikan 
pelayanan untuk menanggulangi kasus kegawatdaruratan obstetri dan neonatal nonstop 24 jam(Anita et al., 2016).

\section{KESIMPULAN}

Perancangan sistem informasi rawat jalan dan pelayanan persalinan berbasis web mampu memaksimalkan keamanan dari orang yang tidak berhak mengakses sistem. Pengembangan sistem pada bidan praktik mandiri menjadi klinik pratama ini dapat digunakan untuk mengolah data pemeriksaan pasien umum, pemeriksaan ibu hamil, ibu melahirkan dan catatan kelahiran bayi serta mampu mengolah laporan kunjungan, laporan penyakit, laporan obat, dan laporan pembayaran.

\section{DAFTAR PUSTAKA}

Anggoro, D., \& Nofiyani. (2016). Analisa dan Rancang Bangun Sistem Informasi Pelayanan Bidan Praktek Swasta (Studi Kasus Bidan Silviana). Jurnal Ilmiah Teknologi Informasi Terapan, III(1), 11-19.

Anita, N., Puspitasari, T. D., \& Aisyabillah, C. P. (2016). Aplikasi Pengolahan Dan Pelayanan Obstetri Neonatal Emergensi Dasar (PONED) Berbasis Desktop. Jurnal Ilmiah Inovasi, 16(2), 128-132. https://doi.org/10.25047/jii.v16i2.297

Aryani, R., Weni, I., \& Saputra, E. (2018). Sistem Informasi Electronic Medical Record (EMR) Berbasis Web Untuk Meningkatkan Kualitas Hasil Diagnosa Penyakit Pasien. Jurnal Sains Dan Sistem Informasi, 1(1), 56-66. Retrieved from $\mathrm{h}$ tt $\mathrm{p} s \mathrm{~s}: / / \mathrm{o}$ n 1 i $\mathrm{n}$ e journal.unja.ac.id/IUSS/article/view/4660

Djuwantono, T., Faried, A., Sutiono, A., Arifin, M., Wirakusumah, F., Yuniarto, S., É Jayadi, Y. (2016). Digitalization Maternal and Prenatal Care Reporting Systems by Using Multimodal Telecommunication Devices for Monitoring Systems in the Rural West Bandung County Indonesia. British Journal of Applied Science $\mathcal{E}$ Technology, 14(3), 1-11. https://doi.org/10.9734/bjast/2016/20762

Faried, A., Sutiono, A. B., Djuwantono, T., Arifin, M. Z., Wirakusumah, F. F., Yuniarto, S. A., É Jayadi, Y. T. (2015). Mother and children health reporting system: Innovative information system application in the rural West Bandung Area, Indonesia, by using multimodal communications systems. 2015 4th International Conference on Instrumentation, Communications, Information Technology, and Biomedical Engineering (ICICI-BME), 202-207. https://doi.org/10.1109/ICICIBME.2015.7401363

Haryanto, \& Firmansyah, A. (2018). Sistem Informasi Pengolahan Data Pasien Berbasis Web Pada Klinik Yadika Tangerang. SinkrOn Jurnal \& Penelitian Teknik Informatika, 2(2), 155-163.

Jatmika, A. H., Afwani, R., \& Agitha, N. (2019). Perancangan Software As A Service (SAAS) untuk Sistem Pelayanan Kesehatan Ibu dan Anak (PKIA) pada Puskesmas Se-Kota Mataram Berbasis Cloud Computing. Jurnal Teknologi Informasi Dan Ilmu Komputer, 6(5), 485. https://doi.org/10.25126/jtiik.2019651589

Karimah, R. N., \& Wicaksono, A. P. (2018). Prototype Sistem Informasi Pelayanan Bayi Baru Lahir pada Fasilitas Kesehatan Primer. Khazanah Informatika: Jurnal Ilmu Komputer Dan Informatika, 4(1), 16-20. https://doi.org/10.23917/khif.v4i1.5330

Kraugusteeliana, K., \& Krisnanik, E. (2018). Sistem Informasi Medical Record Ibu Hamil Dan Anak Pada Puskesmas Panimbang Kabupaten Pandeglang Banten. INFORMATIK Jurnal Ilmu Komputer, 14(3), 113-121.

Kusuma, D. H., Shodiq, M. N., Yusuf, D., \& Saadah, L. (2019). Si-Bidan: Sistem Informasi Kesehatan Ibu dan Anak. INTENSIF: Jurnal Ilmiah Penelitian Dan Penerapan Teknologi Sistem Informasi, 3(1), 43-53.https://doi.org/10.29407/intensif.v $\underline{3 i 1.12508}$ 
Miharti, R., \& Rohmasari, D. R. (2018). Kebutuhan Pengguna dalam Perancangan Disain Antarmuka SIMRS RSU 'Aisyiyah Ponorogo. Jurnal Kesehatan Vokasional, 3(2), 81-89. https://doi.org/https://doi.org/10.22146/j kesvo.38563

Morgan, M., De Jong-Van Den Berg, L. T. W., \& Jordan, S. (2011). Drug safety in pregnancy - monitoring congenital anomalies. Journal of Nursing Management, 19(3), 305-310. https://doi.org/10.1111/j.13652834.2011.01250.x

Ngana, F. R., Myers, B. A., \& Belton, S. (2012). Health reporting system in two subdistricts in Eastern Indonesia: Highlighting the role of village midwives. Midwifery, 28(6), 809-815. https://doi.org/10.1016/j.midw.2011.09.0 $\underline{05}$

Pradhieka, Y., \& Samsinar, S. (2018). Merancang Sistem Informasi Administrasi Rawat Jalan Pada Bidan Nur Indah Novitasari,
Am. Keb. Menggunakan Unifield Modeling Language. IDEALIS: Indonesia Journal Information System, 1(3), 190-196.

Pratiwi, J. D., \& Rokhman, N. (2017). Pengembangan Input Sistem Informasi Kesehatan Ibu dan Anak Berbasis Web di RSKIA Bhakti Ibu Yogyakarta. Jurnal Kesehatan Vokasional, 1(2), 81-86. https://doi.org/10.22146/jkesvo.27573

Rohman, H., \& Agnia, E. (2019). Pelaporan Posyandu Lansia Puskesmas Banguntapan III :Perancangan Sistem Informasi Berbasis Web. 7(2), 44-53.

Soleha, R. E., \& Samsinar, S. (2018). Pemanfaatan Perancangan Sistem Informasi Administrasi Rawat Jalan Pada Bidan Nurma Nugraha, AMd.Keb, SKM. IDEALIS: Indonesia Journal Information System, 1(4), 320-327.

Swastina, L., \& Rizki, J. (2019). Aplikasi Perkiraan Persalinan untuk Meningkatkan Pelayanan Antenatal Care. Jurnal Teknologi Informasi, XIV(2), 72-78. 